\title{
AS DESORDENS SENSÍVEIS NA REVOLUÇÃO ESTÉTICA DE SCHILLER: UMA LEITURA DE RANCIÈRE
}

Lucas Maximiano ${ }^{1}$

Universidade Federal de São Paulo

Resumo: 0 presente artigo tem por objetivo ressaltar a importância da estética, não tanto como o estudo da beleza, da filosofia da arte ou uma teoria da arte, mas que desde o século XVIII é relevante como disciplina autônoma de estudo da sensibilidade enquanto experiência, momento no qual se expande o conceito de estética para a inclusão do político, tornando-se assim fundamento para novas práticas artísticas e a construção de novas formas de vida que percorrerá - como promessa -, toda a modernidade. 0 percurso de exame será a leitura que o filósofo francês Jacques Rancière faz da história das ideias estéticas e seus respectivos regimes, que estão articuladas sobre as noções de estética e política. Essa trama está formulada por meio da ideia de dominação na partilha do sensível dos fazeres, sejam eles artísticos ou não, que desde a República Platônica separava o olhar de um trabalhador diante do mundo do olhar do artista. Rancière separada em três os regimes estéticos da arte, na passagem histórica do regime mimético, para o terceiro regime, se encontra o objeto de análise deste artigo. Rancière encontra na filosofia schilleriana a passagem do regime mimético para o estético, especificamente na dedução que Schiller faz do conceito de bela aparência a partir da suspensão dos conceitos de impulso sensível e formal, por meio do impulso lúdico, o que considerara Rancière ser a cena original de uma verdadeira revolução sensível.

Palavras-chave: Estética. Política. Schiller, Rancière, Partilha do Sensível. XXI V

\footnotetext{
${ }^{1}$ Graduando em filosofia. E-mail: lucas-maximiano1@hotmail.com.
} 
Sensitive disorders in Schiller's aesthetic revolution: a reading by Rancière

Abstract: This article aims to emphasize the importance of aesthetics, not as much as the study of beauty, the philosophy of art or a theory of art but a theme that since the eighteenth century is relevant as an autonomous discipline to study sensibility as an experience, at which point it expands the concept of aesthetics for the inclusion of the politics, thus becoming the basis for new artistic practices and the construction of new forms of life, to all modernity. The course of examination will be the reading that the French philosopher Jacques Rancière makes of the history of aesthetic ideas and their respective regimes, which are articulated on the notions of aesthetics and politics. This plot is formulated through the idea of domination in the separation of the acts' sensible, whether artistic or not, that since the Platonic Republic separated the look of a worker to the world of the artist's look. Rancière separated three aesthetic regimes of art, in the historical passage of the mimetic regime, for the third regime is the object of analysis of this article. Rancière finds in Schiller's philosophy the passage from the mimetic regime to the aesthetic, specifically in Schiller's deduction of the concept of beautiful appearance, from the suspension of the concepts of sensible and formal impulse by means of the ludic impulse, which he considered to be the original scene of a true sensible revolution in aesthetics. This revolution will influence diverse artistic practices and conceptions of culture.

Keywords: Aesthetic. Distribution of the Sensible. Politic. Schiller. Rancière. 
.... Não é fazer de tudo, até arte para alcançar a liberdade, mas fazer de tudo como já se fosse livre - como se tudo fosse arte...

David Graeber.

Em tempos de grandes instabilidades políticas, fins de ciclos e viradas éticas, chamar a atenção para a experiência da beleza na arte, no campo dos fenômenos estéticos, nos aparece de saída um absurdo. Determinados nós, no cenário geopolítico, pelas possibilidades de genocídios por bombas nucleares; e no cenário nacional, pelos indeterminados viravolteios de nossas instituições políticas falidas; como ainda é possível nos desdobrarmos sobre as noções da estéticas? De certo, por ainda ser fundamental. Friedrich Schiller já fizera esta mesma reflexão, quando na Carta Il da Educação Estética, chamou a atenção do leitor para "o palco das belas artes" em meio ao cenário da Revolução Francesa. "Deixando que a beleza preceda a liberdade(...) mostrarei que para resolver na experiência o problema político é necessário caminhar através do estético, pois é pela beleza que se vai a liberdade"². (SCHILLER, 1805,p. 24) Ao relacionar a experiência estética das artes e a revolução, Schiller anuncia a promessa que percorrerá a modernidade: a reconstrução de todo o edifício do político por meio do estético.

Jacques Rancière é um autor contemporâneo muito conhecido no cenário filosófico e pela crítica de arte, justamente por operar com as noções de estética e política em sua filosofia, e não apenas - pois apesar de muitos autores também já terem feito esta articulação -, mas que de tal

\footnotetext{
${ }^{2}$ Friedrich von Schiller, A educação estética do homem, pg. 24
} 
forma ele o faz, que estas noções ocupam a centralidade de seu pensamento. Ele acumula diversos títulos sobre política, cultura e práticas artísticas, mas em maior parte são obras sobre estética. A partilha do Sensível (2000), 0 destino das imagens (2003) 0 mal estar na estética (2004), 0 espectador emancipado (2008) e Aisthesis (2011). A linhagem dos autores com os quais Rancière dialoga é longa e heterotóclita, percorrendo Kant, Schiller, Schelling, Lyotard, Agambem, Luckáks, Adorno e Foucault. Na fortuna crítica da sua obra, o conceito de partilha do sensível é fio condutor para a compreensão dessas noções, em uma expansão do estético abrangendo o político.

$\mathrm{Na}$ "história das ideias estéticas", Rancière separa em três os regimes da arte: o regime ético das imagens, o regime representacional e o regime estético - nos ateremos apenas aos dois últimos -, precisamente na passagem do regime representacional para o regime estético da arte. Jacques Rancière localiza nesta passagem específica uma mudança decisiva, que ocorre e é determinada no século XVIII, a qual defino por Revolução Estética. Friedrich Schiller introduz esta cena original na Filosofia por meio das Cartas da Educação Estética do Homem, a partir da conceituação da suspensão do impulso sensível e formal, sugerindo um terceiro impulso possível a partir desta suspensão. Não confunda-se aqui, a revolução estética de Schiller e a revolução humana, proposta pelas vanguardas marxistas e as vanguardas de 1920. Há uma diferença entre elas: a primeira diz respeito a nova rearticulação conceitual do filósofo, que desenvolve um território filosófico reconhecível, que influenciará a segunda, na definição de um enorme paradigma: a construção de formas de vida, nas quais, a auto exclusão da arte combinaria a auto exclusão da política. Este paradigma ultrapassa o contexto histórico de Schiller, das vanguardas e ressoa, de uma outra maneira, na estética contemporânea.

\section{Blucher}




\section{I) Do Regime Representacional:}

Sobrevoarei a história das ideias estéticas, no período que Jacques Rancière chamou de Regime Representacional, analisando o modo de operação entre, os fazeres, daquilo a que se chamou por "arte verdadeira", a arte que imita a natureza, comparada com outros fazeres, artes e ofícios. Visto que o sistema das belas artes, articulado tanto entorno do conceito de mímesis, opera notadamente, quanto a diferenciação das ocupações sociais, estabelecendo assim, recortes no mundo sensível, no pensável e no dizível comum.

Na República de Platão a figura do artesão não pode tomar parte nas decisões da polis, uma vez que ele não tem tempo para se inserir no interior do espaço político, há em seu fazer uma outra urgência - a do trabalho. Na concepção de Aristóteles o escravo pode perceber o logos nos cidadãos, no entanto ele mesmo não o possui, e pela ausência do logos na sua palavra, que ele não pode tomar para si mesmo a sua parte no ato de governar e ser governado, pois ele não se faz ouvir como voz na discussão e descrição do mundo comum, pois os escravos e artesãos só são ouvidos enquanto "ruídos dos corpos"; dado que aquilo que faz do ser, um ser humano e um ser político é a palavra que evoca o ethos, e na ausência dela, resta ao sujeito apenas a nesta posição de humanidade, de cidadão. 0 domínio do logos, não é entendido como algo discursivo para Rancière, ao contrário disto, o logos é o que confere a partilha da aisthesis, e por isto, permite ao homem - em comunidade -, a aisthesis do bem e do mal, da justiça e da injustiça.

Nesta comunidade das sensações, que comunicam o prazer e o sofrimento, existem aqueles que percebem e os que sentem. 0 logos é compreendido na aisthesis da comunidade, 
como um modo específico e crítico da percepção, como a forma de uma experiência sensível no tempo, de um recorte em um espaço determinado do mundo. Contudo, o escravo não integra a gramática própria da aisthesis do justo e do injusto. Já para Platão, não existe a Arte, mas sim diferentes maneiras de fazeres: artes verdadeiras que imitam a natureza, e outras que são apenas simulacros, e que se limitam a imitar apenas as aparências. 0 artesão não é um artista, e sim um trabalhador. 0 trabalho de seus braços é mais importante do que o trabalho de seus olhos na polis, o seu olhar deve estar, sempre preso, ao trabalho de suas mãos.

Esta é a descrição do regime mimético no domínio das artes representacionais, que separa, fazeres particulares, que pertencem a um modelo específico de maneiras de imitação, criando assim uma normatividade, em que a arte deve copiar modelos. Este regime cria a maneira como as artes devem ser bem feitas e como devem ser bem fruídas. "(...)a mímesis não é a lei que submete as artes à semelhança. É, antes, o vinco da distribuição das maneiras de fazer e das ocupações sociais que torna as artes visiveis." ${ }^{\prime 3}$ (RANCIÈRE, 2009, p.16) Na interpretação de Rancière a mimesis cria uma disjunção entre as belas artes e os outros fazeres - as artes técnicas. A base dessa disjunção está relacionada a uma hierarquização de um sistema socialmente regularizador das ocupações, ou seja, uma "estética primeira" na base da política, capaz de definir a disposição das formas de experiência sensível em determinado tempo e espaço.

Já na idade Média até o Renascimento, nas corporações de artesãos, nas escolas e atelier, os mestres formaram discípulos, que se tornaram mestres e ensinaram a seus discípulos, uma exclusiva herança, os segredos de oficio, dos critérios da simetria e proporção, tanto que,

\footnotetext{
${ }^{3}$ RANCIÈRE, A partilha do sensível, p. 16
} 
comunicavam as categorias de perfeição e a beleza que eram legitimadas pela autoridade da dominação, dentro desta sucessão exclusiva e normativa, definindo o que era ou o que não era arte, o que seria uma experiência estética esperada. No regime mimético descrito, constitui-se a dominação pela desigualdade do sentir. 0 filósofo Voltaire escreve, em um tratado intitulado 0 Gosto, no livro Dicionário Filosófico, que o gosto não é para todos, fazendo com que, desta maneira se diferencie o homem de gosto para o homem comum. 0 homem intelectual, segundo Voltaire, reconhece a beleza. "O gosto, então, como a filosofia, pertence apenas a um grupo de almas privilegiadas. $^{\prime 4}$

É no século XVIII que ocorre a ruptura com o regime representacional - na leitura de Rancière - encerrando assim, com o modo de operação do regime da dominação sensível. A ruptura está fundada no surgimento da autonomia da arte, no qual a natureza não é mais garantia do belo, nem da verdade. A noção de autonomia surge com clareza na filosofia alemã, e o nome de Kant é fundamental. Entretanto, apesar de Kant, na Crítica da Faculdade de Julgar, estabelecer que o "belo é o que agrada sem conceito", ainda podemos pensar se há precisamente uma igualdade no sentir, visto que, na terceira Crítica, Kant explica a experiência estética em dois conceitos, o belo e o sublime. A beleza em Kant é para todos e está relacionada a harmonização das faculdades subjetivas e a sensação de prazer decorrente desta harmonia; o sublime, está relacionado a libertação da escravidão da sensibilidade para a contemplação da natureza infinita, que consegue por meio deste sentimento colocar em movimento as nossas faculdades, que quando entram em jogo, alcançam a direção da descoberta do domínio do incondicionado, que é

\footnotetext{
${ }^{4}$ VOLTAIRE. Dictionary Philosophical: Taste[online].

https://ebooks.adelaide.edu.au/v/voltaire/dictionary/chapter440.html [25/05/2017]
} 
senão a nossa razão. Junto a descoberta da faculdade da razão, esta da mesma forma, a consciência de nossa liberdade a qual, nos possibilita pensar com autonomia e se rebelar contra 0 mundo. No parágrafo vinte e nove da Crítica da Faculdade de Julgar, Kant escreve que o sentimento da beleza pode se esperar de qualquer um, o sentimento do sublime - que possibilita a criação de uma vida livre -, não. Pois o sublime não é uma disposição de ânimo do homem comum.

\section{II) Interlúdio:}

Então, é a partir do final do século XVIII que a arte passa a ser a expressão verdadeira, de pensamentos e paixões, diferentemente dos cânones da representação, do até então regime de dominação das formas, tanto na arte quanto na experiência estética. No quadro Abtei im Eichwald do pintor romântico Casper David, se observa as ruinas de uma Abadia, que são apresentadas neste contexto, enquanto evidência de uma nova relação com o passado. No entorno deste cenário, a natureza está morta, e não é mais lugar, como já fora, de garantia para imitação da verdade e da beleza. Na evidente desarmonia, pelas pinceladas similares, em que os tons se misturam, dificulta-se a visualização de formas e contornos que sejam muito bem delimitados. Já no interior do construtivismo soviético, 0 artista Rodchenko, em ângulos inusitados, fotografa um grupo de trabalhadores por um ângulo aéreo, que achata os seus corpos e homogeiniza seus movimentos, fazendo deles e com eles, a construção de uma equivalência igualitária entre arte e vida. 0 Regime Estético no Brasil apresenta o fotógrafo francês JR, que é muito conhecido no contemporâneo, pelo seu trabalho artístico, com impressões do rosto de pessoas desconhecidas

\section{Blucher}


em formatos gigantescos. Essas fotografias são coladas em lugares como: muros; casas; barracos e veículos. Algumas dessas imagens encontram-se no projeto "Womens are heroes" e são analisadas em um artigo intitulado Rancière e a política das imagens: rosto, olhar e subjetivação na fotografia de JR $R^{6} 0$ espaço público para JR, assim como para Rancière, é o melhor lugar para as suas exposições, uma vez que redefinem os recortes nas cenas do visível, reconfigurando as experiências sensíveis. Daí o aspecto político das obras, que não está no conteúdo que apresentam, mas na reconfiguração de espaços, tempos e visibilidades que a sua forma inusitada produz como efeito. Várias imagens de mulheres foram estampadas nos barracos do Morro da Providência, na favela do Rio de Janeiro. Essas imagens deslocam o olhar do espectador em sua relação com aquela comunidade, pois fazem um rearranjo do sensível, tanto na atividade do olhar lançado a esta comunidade - forma viva -, como tendo sido ela própria, ao mesmo tempo, parte constituidora deste olhar. Está ai, neste aspecto contida a experiência estética da obra, a qual concede um novo estatuto a esta arte. Nesta operação, em um exercício de igualdade, no qual se desassocia o corpo e o espaço de atividades, é que se encontra a emancipação do espectador, que é obra, e no sentido da fabricação é do mesmo modo artista.

\section{III) A Revolução Estética}

$\mathrm{Na}$ leitura de Rancière a ruptura com o regime representacional se deu no momento em que se separou, as formas sensíveis da produção, das formas sensíveis da experiência.

\footnotetext{
${ }^{5} \mathrm{JR}$, Womens are heroes em <http://www.jr-art.net/projects/women-are-heroes-brazil] $>[25 / 05 / 2017]^{6}$ MARQUES, Angela.C.S. e CORREIA, Agatha de S.A., Rancière e a política das imagens: rosto, olhar e subjetivação na fotografia de JR.
} 
Wickelmann é o percursor do novo regime da arte, pois instaura a "distância estética", quando opera na descrição da obra Torso do Belvedere, separando beleza de expressão. Na já citada Crítica da Faculdade de Julgar, quando Kant afirma, que o belo agrada sem conceito ${ }^{6}$, há a consolidação do regime estético. É precisamente nisto a autonomia, não da obra de arte em si, mas de uma experiência.

É no no século XVIII que o nome decisivo de Schiller marca a cena original da estética, na passagem entre o regime representacional para o regime estético da arte. Precisamente no livro $A$ Educação Estético do Homem, com o conceito de arte como bela aparência, aquela que se distancia de todo interesse sexual e da apropriação cognitiva do entendimento, sendo apenas o jogo estético para a fruição livre. Para a dedução de seu conceito de beleza, Schiller parte do eu e do estado de modificação no eu, ou seja, da personalidade do ser ou do vir a ser, na relação com 0 tempo, para chegar ao conceito de homem perfeito, em suas palavras: "O homem, pois, representado em sua perfeição, seria a unidade duradoura que permanece eternamente a mesma nas marés da modificação"'. (SCHILLER, 1805, p. 56)

Dessas duas capacidades na humanidade, modificação e permanência, nascem duas tendências que vão fundamentar as leis da natureza sensivel racional. "A primeira exige realidade absoluta(...) A segunda exige a formalidade absoluta(...)deve exteriorizar todo o seu interior e formar todo o exterior ${ }^{\prime \prime}$. (SCHILLER, 1805, p. 57) Contudo, o homem tem uma dupla tarefa: dar realidade ao necessário em nós e submeter a realidade fora de nós à lei da necessidade,

\footnotetext{
${ }^{6}$ KANT, Crítica da Faculdade do Juízo, p. 64

${ }^{7}$ Friedrich von Schiller, A Educação Estética do Homem, p.56

${ }^{8}$ Friedrich von Schiller, A Educação Estética do Homem, p.57 ${ }^{10}$

Johann Gottlieb Fitche
} 
movimento este que será realizado por duas forças opostas: 0 impulso sensível e o impulso formal. 0 primeiro impulso diz respeito sobre a nossa existência sensível, tenta tornala matéria no tempo, que exige mutação e tem como objeto a vida. ${ }^{10}$ Na perspectiva de Rancière esta seria a parte da humanidade que sente, por uma determinação passiva diante do mundo. 0 segundo diz sobre a nossa existência racional, quer colocá-la em liberdade através da harmonia à multiplicidade dos fenômenos, o qual exige imutabilidade e o seu objeto é a forma. Esta porção seria a humanidade que pensa por uma determinabilidade ativa da vontade. Diante dessa oposição originária, Schiller pergunta: "como reconstituiremos a unidade da natureza humana, que parece completamente suprimida por esta oposição originária e radical?"' (SCHILLER,

1805, p. 63) Como solução, Schiller postula a possibilidade de um "terceiro impulso" que possa mediar esses dois impulsos, o que só poderá ocorrer pela distensão de ambos.

\begin{abstract}
"O impulso sensivel quer que haja modificação, que o tempo tenha conteúdo; 0 impulso formal quer que o tempo seja suprimido, que não haja modificação. 0 impulso em que os dois atuam juntos (seja me permitido chama-lo de impulso lúdico até que justifique a denominação), este impulso lúdico seria direcionado, portanto a suprimir o tempo no tempo, a ligar o devir ao ser absoluto a modificação à identidade ${ }^{\prime \prime 10}$ (SCHILLER, 1805, p.70)
\end{abstract}

0 impulso fundamental que harmoniza o impulso sensível e o formal é o impulso lúdico, que não é um terceiro impulso ao lado dos dois, mas a capacidade de colocá-los em jogo; o impulso lúdico tem como objeto a forma viva.

\footnotetext{
${ }^{9}$ Friedrich von Schiller, A Educação Estética do Homem, p. 63

${ }^{10}$ Friedrich von Schiller, A Educação Estética do Homem, p. 70
} 
"A razão, entretanto, diz: o belo não deve ser mera vida ou mera forma, mas forma viva, isto é, deve ser beleza à medida que dita ao homem a dupla lei da formalidade e realidade absolutas. Com isso, ela afirma também: 0 homem deve somente jogar ${ }^{11}$ com a beleza, e somente com a beleza jogar. Pois para dizer tudo de vez, o homem joga somente quando é homem no pleno sentido da palavra e somente homem pleno quando joga." ${ }^{12}$ (SCHILLER, 1805, p.76)

A suspensão estética schilleriana, através do jogo entre os impulsos, sensível e formal é nomeada por Rancière de partilha do sensível. Quando Schiller suspende o impulso sensível e 0 impulso formal, cria-se a partir disto, a suspensão do poder cognitivo do entendimento sobre a sensibilidade, e não apenas, mas a suspensão nas diferenças sensíveis dentro da comunidade, apontando para um estado estético possível, onde a humanidade, em seu estado lúdico, pode ser livre percorrendo um estado de mera determinabilidade. A igualdade do sentir instituída pela filosofia schilleriana, destrói pois, todas as hierarquias da representação e da comunidade antiga, anteriormente constituída na desigualdade dos fazeres, fundando uma outra comunidade, baseada na igualdade do sentir. 0 regime estético rompe com uma visão hierárquica da sociedade na qual alguns pensam e outros sentem, alguns falam outros produzem ruídos, atividade e passividade, sensação e inteligência, o homem intelectual do homem comum.

Na revolução estética, por uma viravolta do neoclassicismo, a concepção de obra de arte se aproxima muito do regime ético, em que a obra esteve vinculada ao ethos da comunidade, mas

\footnotetext{
${ }^{11}$ A ideia da contemplação estética como "livre jogo" (jogo entre a imaginação e o entendimento; livre, porque não sujeito a regras ou conceitos) foi apresentada por Kant na Crítica do Juízo. Schiller, como se vê, radicaliza essa ideia, entendendo 0 impulso lúdico como um jogo entre as capacidades racionais e sensíveis do homem, e a ausência de regras ou conceitos como uma verdadeira "liberdade humana. A Educação Estética do Homem pg. 147 [Notas]

${ }^{12}$ Friedrich von Schiller, A Educação Estética do Homem, pg. 76
}

\section{Blucher}


ela se articula de outra maneira, pois a obra tem no regime estético individuação e autonomia. A arte ganha então no regime estético um status ontológico, por meio de uma individuação que a autonomiza, e assim ganha potência heterogênea, pois torna-se - a arte - estranha a si mesma, torna-se uma outra coisa, quando é arte não sendo. Ela é desobrigada de qualquer regra específica ou de temas pertencentes a uma hierarquia.

Nesta inversão das hierarquias da representação se declara o fim da mímesis. Na leitura de Rancière, Schiller é quem, ao articular as preposições da analítica do belo kantiana, para 0 contexto da Revolução Francesa, produz uma nova ideia de revolução política possível, baseada na igualdade do sentir, na qual, as potências da obra de arte e de uma experiência estética seriam capazes de ser a base deste novo estado a ser fundado em um vir a ser.

\section{IV) Do Regime Estético :}

0 Regime estético é então, o regime das noções de autonomia e da heteronomia da arte e da experiência estética já formuladas por Friedrich Schiller, que rearranjam todo o fazer artístico desde o século XVIII. Apontarei, sem muita pretensão, as consequências das leituras feitas pelas vanguardas artísticas modernistas que, influenciadas por este cenário original da estética schilleriana, receberam como escopo a promessa da constituição de uma nova forma de vida, mas esse não será todo o nosso objetivo dado a amplitude do tema; que desemboca também na falência deste projeto revolucionário - o qual está relacionado com a ideia de formas de vida se tornando arte e arte se tornando formas de vida, neste limiar, que a arte é arte enquanto que ela também não é arte. 
Rancière aponta que a autonomia organizada no regime estético, não é tanto a autonomia da obra de arte, mas sim a autonomia de uma experiência, no cenário em que a arte se torna vida. Rancière reconhece a autonomia da experiência estética em uma acepção do programa sistemático do idealismo alemão, que consistia na constituição de um novo etos coletivo. "Agora, o cumprimento dessa promessa está identificado com o ato de um sujeito que se livra de todas as aparências, que eram somente 0 sonho de algo que ele agora deve possuir na realidade."13 (RANCIÈRE, 2002, p.9) Na nova era da igualdade, a coletividade seria então, ela mesma, uma obra de arte. As vanguardas marxistas e as vanguardas de 1920 tinham em comum construir formas de vida que levariam a exclusão da arte e da política.

Esta experiência de autonomia está relacionada a experiência sensível de um espectador. Espectador emancipado desde o século XVIII pois, se a arte existe como tal, como um mundo próprio, não só ao artista é dado o poder de fazer, de inventar e experimentar, como abre-se ao espectador a possibilidade de reconhecer e combinar diferentes superfícies em uma.

\section{V) Conclusão:}

Para concluir, observaremos a leitura de Rancière da décima quinta carta da Educação Estética, a qual versa a respeito do "aspecto livre" da estátua grega Juno Ludovisi. 0 que se segue é a experiência estética fruída por Schiller que é apresentada ao seu leitor com singularidade. Faço uso da concepção de sensorium da deusa concebida por Rancière. As características da

\footnotetext{
${ }^{13}$ RANCIÈRE, J. A revolução estética e os seus resultados. pg. 9
} 
divindade, assim como da escultura são: a futilidade, a ausência de vontade e intenção. $\mathrm{Na}$ ausência de qualquer desejo, a estátua representa e contém em sua autonomia, ao mesmo tempo, as qualidades daquilo que não é arte, e apesar disto, o espectador-leitor encontra uma experiência de outra autonomia de um tipo muito especial, a de sua própria fruição. "(...)encontramo-nos simultaneamente no estado de repouso e movimento máximos, surgindo aquela maravilhosa comoção para a qual o entendimento não tem conceito e a linguagem não tem nome. ${ }^{114}$ (SCHILLER, 1805, p.81)

A autonomia relevante para Rancière, não é a da obra, mas sim a de uma experiência, que está relacionada a revogação de poder da dominação. 0 aspecto livre da obra fica inacessível ao desejo do espectador e the resta apenas a promessa de um mundo novo que ele jamais poderá possuir. "A deusa e o espectador, o jogo livre e o aspecto livre, são pegos juntos em um sensorium específico, anulando as oposições entre atividade e passividade, vontade e resistência. "15 (RANCIÈRE, 2002, p.5)

A obra grega é arte não sendo, encontra-se no aspecto de não ser obra e que me interessa, uma sociabilidade que não está baseada na dominação do sentir, nem na separação dos fazeres, mas justamente na suspensão, em sua autossuficiência, propõe uma vida sensível coletiva onde, arte e vida, assim como política e arte, vida e política não estejam separadas, em que a arte em seus produtos, é agora vida. Isto é a Educação Estética na qual Schiller expõem a trama em que a humanidade primitiva começa a mudar o seu olhar para seus braços, para as suas ferramentas, para as suas atividades, de uma forma determinada à uma forma estética. Se

\footnotetext{
${ }^{14}$ SCHILLER, F. A educação estética do homem. pg. 81

${ }^{15}$ RÀNCIERE, Jacques. A revolução estética e suas consequências. Pg. 5
} 
lançando para fora da materialidade, porque tem a capacidade de transformar o mundo em seu próprio sensorium. São nestes momentos de desordens sensíveis que se criam experiências de emancipação excepcionais e revolucionários.

\section{VI) BIBLIOGRAFIA:}

HURAD0, Jordi Carmona. Às origens da partilha do sensível: 0 trágico o sublime e a melancolia, org. Verlaine Freitas, Rachel Costa, Debora Pazetto. vl. 2 - Belo Horizonte, MG: Relicário Edições, 2016

KANT, Immanuel. Crítica da faculdade do juízo. Tradução de Valério Rohden e António Marques. $1^{\text {a }}$ Edição. Rio de Janeiro: Forense Universitária, 1993.

MAROUES, Angela.C.S. e CORREIA, Agatha de S.A., Rancière e a política das imagens: rosto, olhar e subjetivação na fotografia de JR.

RANCIÈRE, Jacques. 0 espectador emancipado; tradução Ivone C. Benedetti. - São Paulo: Editora Martins Fontes, 2012

RANCIÈRE, Jacques. A revolução estética e seus resultados [online]. Projeto Revoluções, http://www.revolucoes.org.br/v1/sites/default/files/a_revolucao_estetica_jacques_ranciere.pdf, [15/10/2014], 2002.

RANCIÉRE, Jacques. A partilha do sensível. São Paulo: Editora 34, 2005.

RICADO, Barbosa. Schiller e a cultura estética. Rio de Janeiro: Jorge Zahar Ed., 2004. (Filosofia Passo-a-passo).

\section{Blucher}


SCHILLER, Friedrich, A Educação Estética do Homem: numa série de cartas. São Paulo:

Iluminuras, 2013

. Friedrich. Cultura estética e liberdade. São Paulo, Hedra, 2009.

VOIGT, A. Fabiano. A estética em Jacques Rancière e a questão da mímesis.

VOLTAIRE. Dictionary Philosophical: Taste[online].

https://ebooks.adelaide.edu.au/v/voltaire/dictionary/chapter440.html [25/05/2017] 